Received: 15 March 2017

Accepted: 17 May 2017

Published online: 27 June 2017

\section{Quantitative Assessment of Hydrological Alteration Caused by Irrigation Projects in the Tarim River basin, China}

\author{
Lianqing Xue ${ }^{1,2}$, Hui Zhang ${ }^{1}$, Changbing Yang ${ }^{3}$, Luochen Zhang ${ }^{4}$ \& Chao Sun ${ }^{4}$ \\ The Tarim River is the longest inland river at an arid area in China. Deterioration in its ecohydrological \\ system has received much attention world widely. This study presents quantitative assessment of \\ hydrological alterations in the hydrological regime of the Tarim River caused by reservoir irrigation and \\ channel irrigation over a period of over a half century. The improved indicators of hydrologic alteration \\ and range of variability approach were applied to the daily flow rates at the two representative \\ hydrological stations. Our study shows that the annual extreme water conditions (1-, 3-, 7-day annual \\ minimum and extreme low timing) have been altered, compared with the pre-impact period. The \\ average flow rate in July, the 30-day annual maximum flow rates, the date for the maximum rate, \\ the rise rate, and the fall rate show a significant decreasing trend. The improved overall degree of \\ hydrological alteration for the two stations are approximately $68.7 \%$ and $61.8 \%$, suggesting a high \\ degree of alteration. This study greatly improved our understanding of impacts of irrigations on the \\ ecohydrological characteristics in the Tarim River.
}

Shortage in freshwater resources has become one of the prominent issues in many regions of the world, especially in developing countries, such as China ${ }^{1,2}$. With economic development, demand in freshwater resources is increasing continuously and posing tremendous pressure on water resources management. In the past, development of water resources projects at various scales has been considered a solution strategy for mitigating shortage in water supply, especially, in Northwestern China where water division projects have been built on most major rivers over the last half century ${ }^{3,4}$. Because the water needs of humans and natural ecosystems are generally considered as competing with each other, the over usage of water by humans could lead to severe alterations to the ecohydrological regimes of a river system. Many examples of ecological consequences of altered natural flow regimes have been reported in literature ${ }^{5-7}$.

Many efforts have been devoted to quantitatively assess the anthropogenic impacts on water environments with more than 170 hydrologic metrics to describe different components of flow regime and characterize the ecologically relevant attributes ${ }^{8-10}$. In the last two decades, the most commonly used hydrologic indices for characterizing flow regimes are the Indicators of Hydrologic Alteration (IHA) ${ }^{11-13}$. The IHA includes 32 parameters which can be categorized into five groups of hydrologic features, covering a full range of natural flow variability, from magnitude, frequency, timing, duration to rate of change ${ }^{14,15}$. A comprehensive review conducted by Olden and Poff ${ }^{9}$ concluded that the IHA can adequately characterize flow regimes with ecological knowledge and greatly improve our understanding of the interactions between flow regimes and riverine ecosystems. The Range of Variability Approach (RVA), proposed by Richter et al. ${ }^{16}$, is a widely used approach for quantitatively assessing the alteration of flow regime by comparing frequency distributions of IHA parameters during the pre-impact and post-impact ${ }^{17-20}$. The river managers try to evaluate potential hydrologic alterations within a targeted range which is related to the natural range of variability in parameters. Each IHA has the range of variability which can be determined based on the selected percentile thresholds or a simple standard derivations by the $25^{\text {th }}$ and $75^{\text {th }}$ percentiles of the pre-impact IHA values. 


\begin{tabular}{|c|c|c|c|c|c|c|c|c|c|c|c|c|c|c|}
\hline \multirow[b]{3}{*}{ Indicators } & \multicolumn{7}{|c|}{ The Alar station } & \multicolumn{7}{|c|}{ The Xinquman station } \\
\hline & \multirow{2}{*}{\begin{tabular}{|l|} 
Pre-impact \\
$\mathbf{M}$
\end{tabular}} & \multicolumn{3}{|c|}{ RI impact } & \multicolumn{3}{|c|}{ CI impact } & \multirow{2}{*}{$\begin{array}{l}\text { Pre-impact } \\
M\end{array}$} & \multicolumn{3}{|c|}{ RI impact } & \multicolumn{3}{|c|}{ CI impact } \\
\hline & & M & $\mathbf{P}(\%)$ & D (\%) & M & $\mathbf{P}(\%)$ & $\mathrm{D}(\%)$ & & M & $\mathbf{P}(\%)$ & D (\%) & M & $\mathbf{P}(\%)$ & D (\%) \\
\hline January & 70.1 & 77.2 & 10 & 54 & 25.5 & -64 & 87 & 62.3 & 53.4 & -14 & 0 & 11.5 & -82 & 100 \\
\hline February & 65.0 & 69.3 & 7 & 38 & 30.8 & -53 & 74 & 72.3 & 58.9 & -18 & 0 & 15.9 & -78 & 100 \\
\hline March & 60.2 & 29.6 & -51 & 69 & 32.2 & -47 & 100 & 58.1 & 41.3 & -29 & 57 & 16.9 & -71 & 100 \\
\hline April & 12.3 & 13.7 & 11 & 7 & 22.4 & 82 & 87 & 16.9 & 10.9 & -36 & 57 & 12.0 & -29 & 51 \\
\hline May & 11.4 & 9.7 & -15 & 99 & 31.7 & 178 & 74 & 5.6 & 6.4 & 14 & 29 & 17.6 & 214 & 88 \\
\hline June & 112.5 & 9.8 & -91 & 100 & 80.1 & -29 & 22 & 42.4 & 4.7 & -89 & 14 & 57.1 & 35 & 9 \\
\hline July & 350.0 & 394.0 & 13 & 100 & 311.5 & -11 & 9 & 300.0 & 223.0 & -26 & 86 & 208.4 & -31 & 39 \\
\hline August & 657.0 & 589.0 & -10 & 69 & 565.5 & -14 & 74 & 530.0 & 544.0 & 3 & 43 & 509.0 & -4 & 39 \\
\hline September & 176.9 & 116.0 & -34 & 39 & 199.0 & 12 & 61 & 166.5 & 129.5 & -22 & 29 & 211.5 & 27 & 51 \\
\hline October & 68.9 & 85.6 & 24 & 24 & 68.6 & 0 & 43 & 53.0 & 62.6 & 18 & 29 & 57.3 & 8 & 27 \\
\hline November & 63.2 & 35.6 & -44 & 69 & 22.7 & -64 & 100 & 45.9 & 31.4 & -32 & 100 & 16.6 & -64 & 100 \\
\hline December & 94.6 & 91.0 & -4 & 22 & 28.1 & -70 & 100 & 59.3 & 61.2 & 3 & 14 & 12.1 & -80 & 100 \\
\hline
\end{tabular}

Table 1. Comparison of hydraulic alterations in Group 1 IHAs (monthly streamflow) at the two stations for the pre-impact, RI impact and CI impact. Note: $\mathrm{M}$ for median value, $\mathrm{P}$ for deviation degree estimated using Equation (1), D for degree of hydrological alteration estimated with Equation (2), RI for Reservoir irrigation, and CI for Channel irrigation.

The primary objective of this study is to assess hydrological alterations of flow regimes in terms of 32 IHAs with the RVA due to water division projects for irrigation at the Tarim River Basin. The TRB is located in the northwest arid area of China, exhibiting a fragile ecological environment ${ }^{21,22}$. The Tarim River is the longest inland river in China with a mainstream of $1321 \mathrm{~km}$ in length. Over the last half century, because of intensive human interventions, such as water exploitation and utilization with various water division projects, the natural ecological processes have experienced severe changes and the significant imbalance in the natural distribution of water resources has become one of great concerns by public ${ }^{23}$. Many studies about impacts of human activities and climate change on the ecological and water systems at the TRB were reported ${ }^{24-40}$. Chen et al. ${ }^{41}$ presented a study about desiccation of the Tarim River showing an increasing trend in length affected and time duration and concluded that water transfer to the lower reach will be severely impacted if the tendency is not constrained and the downstream "Green Corridor" protection will be severely impacted. Qi et al. ${ }^{42}$ reported that intensive anthropogenic disturbance has been one of the foremost factors leading to deterioration of water resources in the region. Tao et al. ${ }^{43}$ evaluated ecohydrological responses to water diversion in the lower reaches of the Tarim river using groundwater wells and vegetation as main indicators. However, up to date there are very few studies reported on quantitative assessment of hydrologic alterations of flow regimes in the Tarim River due to water diversion projects for irrigation at the basin. Sun et al. ${ }^{44}$ analyzed long streamflow series collected from 5 hydrological stations in the Tarim River in terms of the only one hydrological parameter, the 7-day low flow. Late, Wang et al. ${ }^{22}$ assessed streamflow changes in the Tarim River basin based on daily data collected at 7 hydrological stations, but focused on trends in hydrological extremes, including magnitude, duration and high flow frequency. In this study, the extended streamflow data during 1957 through 2014 were comprehensively assessed in terms of 32 IHAs to characterize hydrological alterations between pre-impact and post-impacts of water diversion projects. In addition, the post-impacts were further divided into two phases: the reservoir irrigation and channel irrigation. To the best of our knowledge, the study presented here is the first kind of comprehensive assessment on hydrological alterations of flow regimes in the Tarim River.

\section{Results}

Impacts on the magnitude of monthly streamflow. The median value, deviation degree and degree of alteration for the monthly streamflow of the Group 1 IHAs at the Alar station and the Xinquman station are listed in Table 1. Deviation degree and degree of alteration for each IHA were calculated with Equations (1) and (2). At the Alar station, except in January, February, April, and July, the stream flow in the other months decreased from the pre-impacted period to the RI impacted period (Table 1). The most significant decrease in the stream flow occurred in June, from $\sim 113 \mathrm{~m}^{3} / \mathrm{s}$ during the pre-impacted period to $\sim 10 \mathrm{~m}^{3} / \mathrm{s}$ during the RI impacted period (Fig. 1a). At the Xinquman station, the RI and CI impacts on median value of monthly stream flow show a similar pattern at the Alar station (Fig. 1b). At the Alar station, during the RI impact period the deviation degree $(P)$ for 7 out of 12 months is less than 0 while during the CI impacted period deviation degree for 9 out of 12 months is a negative value, suggesting the that both reservoir irrigation and channel irrigation have decreased the stream flow rate in the Tarim River, compared to the natural condition during the pre-impacted period. At the Xinquman station, deviation degree is less than 0 for 8 out 12 months during both the RI and CI impacted periods (Fig. 1d).

At the Alar station, calculation of degree of hydrological alteration (D) for monthly stream flow shows that 3 monthly stream flows fall within the category of low alteration $(\mathrm{D}<33 \%)$, 3 within the category of moderate alteration $(33 \%<\mathrm{D}<67 \%)$ and 6 within the category of highly alteration $(\mathrm{D}>67 \%)$ during the RI impacted period while 2 within the category of low alteration, 2 within the category of moderate alteration and 8 within the category of highly alteration during the CI impacted period (Table 1). At the Xinquman station, 2 monthly stream flows (July and November) are highly altered with $\mathrm{D}>67 \%$ during the RI impacted period while 6 monthly 
a) Alar

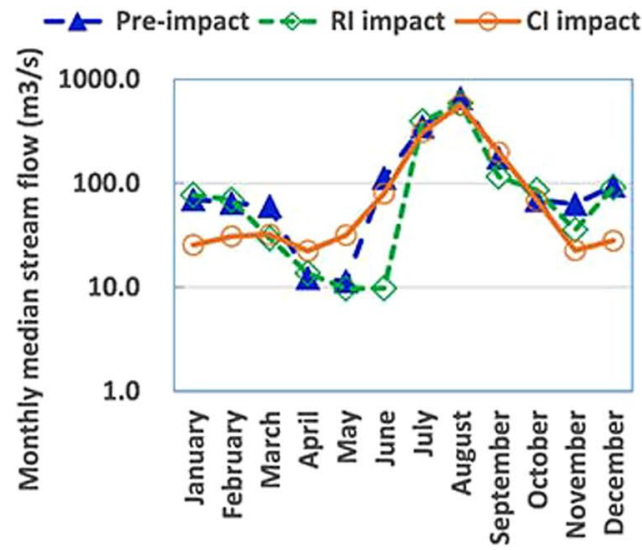

c) Alar
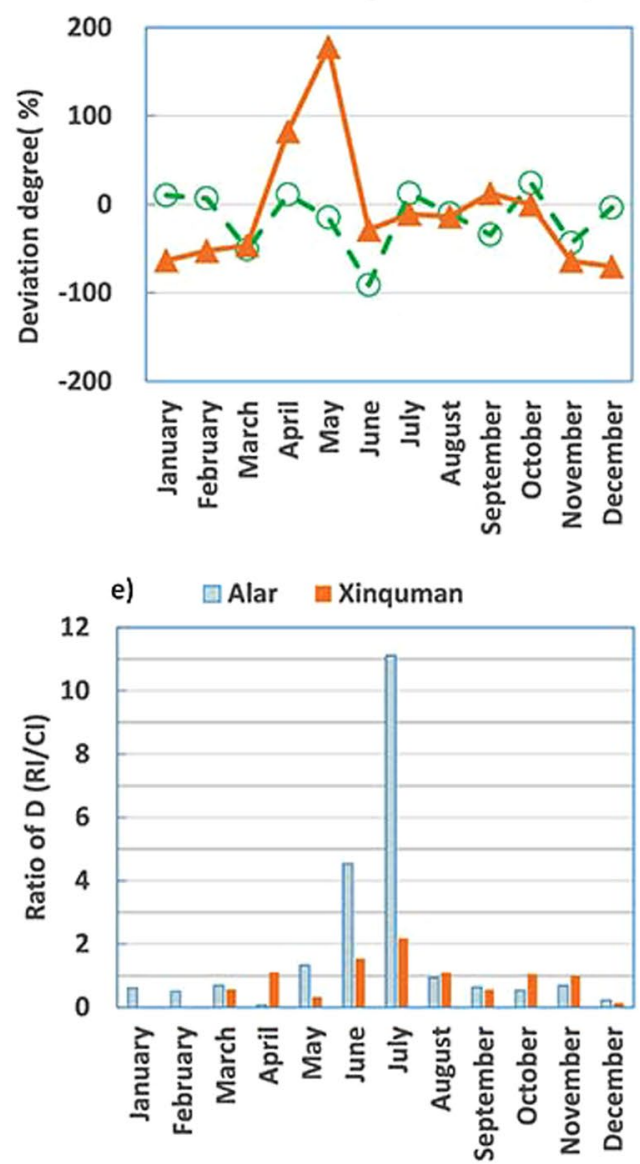

b) Xinquman

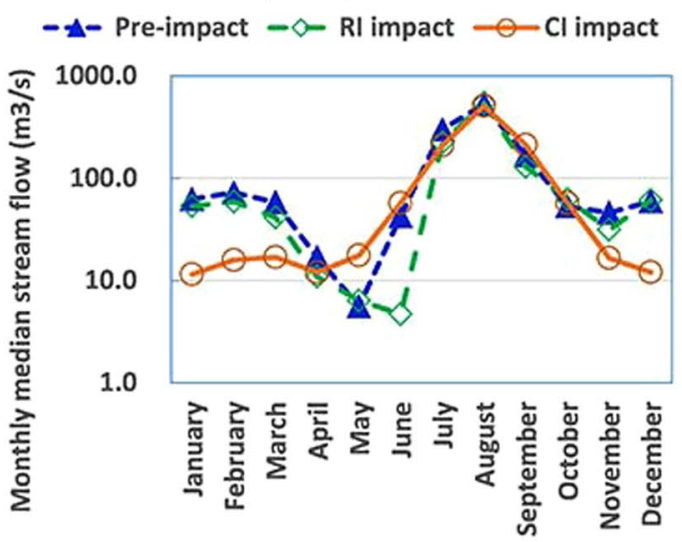

d) Xinquman $\quad-\infty$ Rl impact $\rightarrow-\mathrm{Cl}$ impact
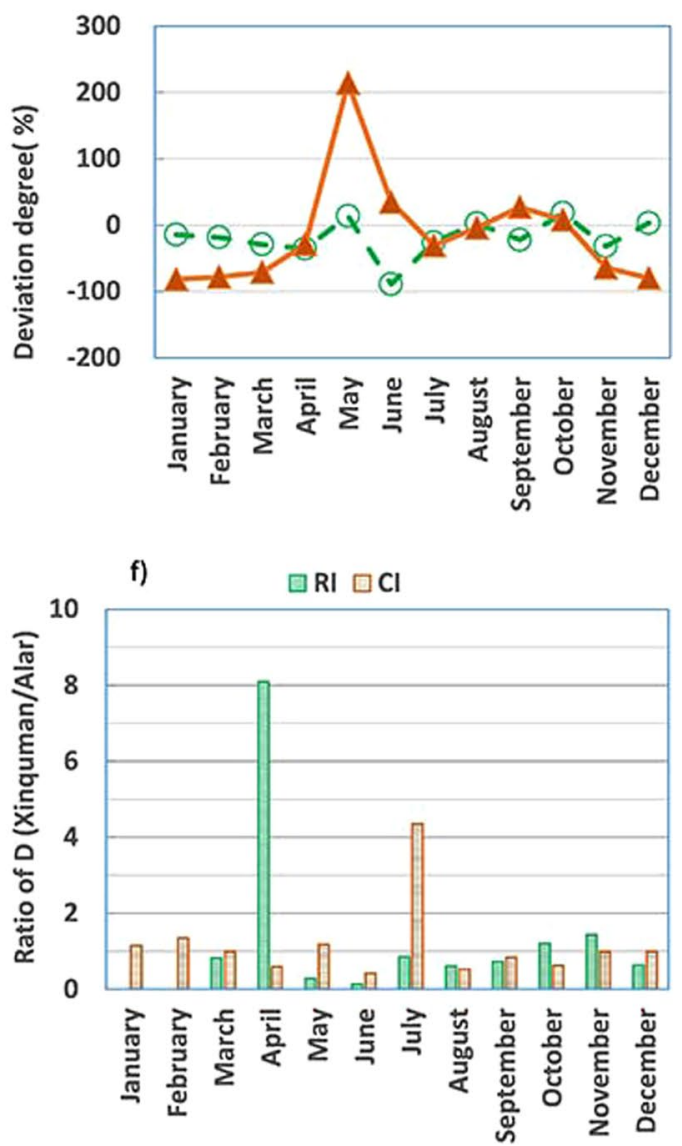

Figure 1. Plots of median monthly stream flow at (a) the Alar station and (b) at the Xinquman station, deviation degree of median monthly stream flow (c) at the Alar station and (d) at the Xinquman station, ratio of degree of hydraulic alteration (e) for the RI impact to the CI impact, and (f) between the two stations (note: RI for reservoir irrigation from 1973 to 1989 and CI for channel irrigation from 1995 to 2014).

stream flows are highly altered during the CI impacted period. Figure 1e shows comparison between the impacts of reservoir irrigation and channel irrigation on the monthly stream flow in the Tarim River in terms of $\mathrm{D}$ ratio (=D during the $\mathrm{RI}$ impacted period/D during the $\mathrm{CI}$ impacted period). If $\mathrm{D}$ ratio is greater than 1 , this suggests that RI has more significant impacts on monthly stream flow than CI. Obviously the D ratios in June and July are greater than 1 at both stations (Fig. 1e), suggesting that RI has stronger impacts on the monthly stream flows than $\mathrm{CI}$ does. On the other hand, $\mathrm{D}$ ratios in December at both stations are close to 0.2 , indicating that CI has more significant impacts on the monthly stream flow than RI does. 


\begin{tabular}{|c|c|c|c|c|c|c|c|c|c|c|c|c|c|c|}
\hline \multirow[b]{3}{*}{ Indicators } & \multicolumn{7}{|c|}{ The Alar station } & \multicolumn{7}{|c|}{ The Xinquman station } \\
\hline & \multirow{2}{*}{\begin{tabular}{|l|} 
Pre-impact \\
M \\
\end{tabular}} & \multicolumn{3}{|c|}{ RI impact } & \multicolumn{3}{|c|}{ CI impact } & \multirow{2}{*}{$\begin{array}{l}\text { Pre-impact } \\
\text { M }\end{array}$} & \multicolumn{3}{|c|}{ RI impact } & \multicolumn{3}{|c|}{ CI impact } \\
\hline & & M & $\mathbf{P}(\%)$ & D (\%) & M & $\mathbf{P}(\%)$ & D (\%) & & M & $\mathbf{P}(\%)$ & D (\%) & M & $\mathbf{P}(\%)$ & D (\%) \\
\hline 1-day minimum & 5.3 & 6.0 & 13 & 49 & 11.7 & 120 & 100 & 2.0 & 2.6 & 33 & 43 & 2.4 & 22 & 39 \\
\hline 3-day minimum & 5.4 & 6.0 & 10 & 39 & 12.0 & 120 & 74 & 2.0 & 2.7 & 36 & 29 & 2.5 & 25 & 27 \\
\hline 7-day minimum & 5.5 & 6.2 & 13 & 24 & 12.2 & 124 & 87 & 2.1 & 2.8 & 34 & 29 & 2.6 & 22 & 15 \\
\hline 30-day minimum & 9.3 & 7.6 & -18 & 39 & 16.6 & 79 & 100 & 4.5 & 5.1 & 13 & 71 & 5.1 & 13 & 34 \\
\hline 90-day minimum & 30.5 & 13.9 & -55 & 7 & 23.5 & -23 & 69 & 18.1 & 10.2 & -44 & 14 & 8.7 & -52 & 3 \\
\hline 1-day maximum & 1090 & 1330 & 22 & 24 & 1170 & 7 & 17 & 1020 & 863.0 & -15 & 14 & 969.5 & -5 & 64 \\
\hline 3-day maximum & 1013 & 1267 & 25 & 24 & 1047 & 3 & 4 & 1008 & 821.3 & -19 & 0 & 897.4 & -11 & 27 \\
\hline 7-day maximum & 944.1 & 1123 & 19 & 8 & 962 & 2 & 9 & 832.1 & 765.7 & -8 & 0 & 841.1 & 1 & 3 \\
\hline $\begin{array}{l}\text { 30-day } \\
\text { maximum }\end{array}$ & 726.0 & 773 & 6 & 85 & 669 & -8 & 61 & 603.2 & 566.2 & -6 & 29 & 592.9 & -2 & 3 \\
\hline $\begin{array}{l}\text { 90-day } \\
\text { maximum }\end{array}$ & 446.8 & 430.4 & -4 & 69 & 425.3 & -5 & 87 & 400.3 & 342.1 & -15 & 43 & 357.4 & -11 & 64 \\
\hline Base flow index & 0.032 & 0.051 & 60 & 7 & 0.102 & 218 & 100 & 0.016 & 0.024 & 55 & 43 & 0.02 & 57 & 3 \\
\hline $\begin{array}{l}\text { Julian date of } \\
\text { minimum }\end{array}$ & 143 & 163 & 14 & 24 & 184 & 29 & 48 & 159 & 176 & 11 & 71 & 148 & -7 & 88 \\
\hline $\begin{array}{l}\text { Julian date of } \\
\text { maximum }\end{array}$ & 226 & 220 & -3 & 39 & 217 & -4 & 9 & 226 & 222 & -2 & 14 & 218 & -4 & 27 \\
\hline
\end{tabular}

Table 2. Comparison of hydraulic alterations in extreme flow conditions (Groups 2 and 3) at the two stations for the pre-impact, RI impact and CI impact. Note: $\mathrm{M}$ for median value, $\mathrm{P}$ for deviation degree estimated using Equation (1), D for degree of hydrological alteration estimated with Equation (2), RI for Reservoir irrigation, and CI for Channel irrigation.

Degree of hydrological alteration of the monthly stream flow at the Alar station is also compared to that at the Xinquman station in terms of their ratio, D during the RI (or CI) impacted period at the Xinquman station divided by D during the RI (or CI) impacted period at the Alar station. If the ratio $>1$, this indicates that the post impact (either RI or CI) on the monthly stream flow is more significant at the Xinquman station than at the Alar station. Apparently, reservoir irrigation has more significant impact on the monthly stream flow in April with a ratio up to 8 and channel irrigation has more significant impact on the monthly stream flow in July with a ratio up to 4 at the Xinquman station than at the Alar station. In June, both RI and CI have stronger impact on the monthly stream flow at the Alar station than at the Xinquman station (Fig. 1f). The results show clearly that the impacts of RI and CI on monthly runoff are significant, and the operation of reservoirs could decrease the magnitude of runoff.

Hydrologic alteration for the annual extreme flow conditions. Table 2 lists median value, deviation degree and degree of hydraulic alteration for the annual extreme flow conditions including 11 IHAs in the Group 2 and 2 IHAs in the Group 3 at the Alar station and the Xinquman station.

Figure 2 illustrates impacts of RI and CI on the annual extreme flow conditions in the Tarim River at the Alar station. It seems that the 1 -day minimum was elevated by $13 \%$ during the RI impacted period and $120 \%$ during the CI impacted period at the Alar station (Fig. 2a). However, the date with 1-day minimum stream flow was slightly delayed ( $\sim 20$ days) during the RI impacted period and significantly delayed ( $\sim 40$ days) during the CI impacted period at the Alar station (Fig. 2b). At the Alar station, 9 out of 13 IHAs have a positive deviation degree during both the RI and CI impacted periods. The base flow index has a highest deviation degree, up to $220 \%$ during the CI impacted period (Fig. 3a). At the Xinquman station, 6 out of 13 IHAs have a positive deviation degree during both the RI and CI impacted periods. Similar to that at the Alar station, the base flow index has the maximum deviation, up to $\sim 57 \%$ for both the RI and CI impacted periods (Fig. 3 b), suggesting that the date with minimum stream flow was likely postponed from the late of April to early June.

At the Alar station, 7 IHAs (7-, 90-day minimum, 1-, 3-, 7-day maximum, base flow index, Julian date of minimum) show low alterations with $\mathrm{D}<33 \%$ and 2 IHAs (the 30-, and 90-day maximum) show highly alterations with $\mathrm{D}>67 \%$ during the RI impacted period. However, during the CI impacted period, 7 IHAs show highly alterations with $\mathrm{D}>67 \%$ (Table 2). At the Xinquman station, during the RI impacted period 2 IHAs (Julian date of minimum and 30-day minimum) show highly alterations with $\mathrm{D}>67 \%$ and during the CI impacted period only one IHA (Julian date of minimum) shows highly alteration. Figure $3 c$ shows the D ratio of each IHA among the Groups 2 and 3 between the RI impacted and the CI impacted periods at the two stations. At the alar station, 4 IHAs have a D ratio greater than 1 while at the Xinquman station, 7 IHAs have a D ratio greater than 1, suggesting that compared to CI, RI has stronger impacts on the extreme flow conditions at the Xinquman station than at the Alar station (Fig. 3c). Figure 3d shows comparison between the two stations in terms of degree of hydraulic alteration. Obviously, RI has more significant impacts on the 7-, 30-, 90-day minimum, base of index and date of minimum at the Xinquman station than at the Alar station. CI altered 1-, 3-day maximum, date of minimum, and date of maximum more significantly at the Xinquman station than at the Alar station. 

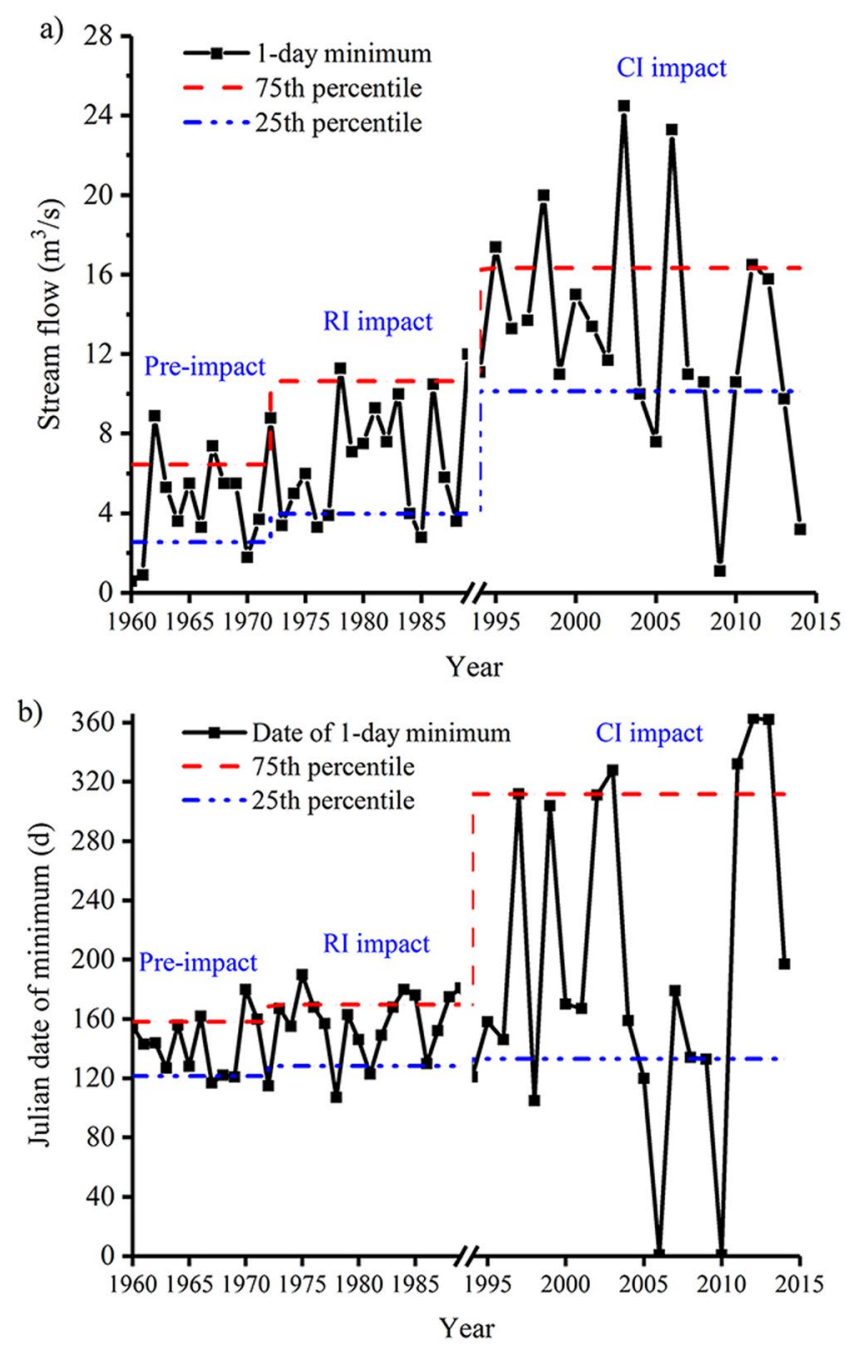

Figure 2. Plots of (a) 1-day minimum stream flow and (b) Julian date of minimum stream flow occurrence at the Alar station.

Hydrologic alteration of frequency and duration of high and low pulses. Assessment of impacts of RI and CI on the indicators in Group 4 in terms of deviation degree and degree of hydraulic alteration is listed in Table 3. At the Alar station, both RI and CI show similar impacts on the frequency and duration of high and low pulses in terms of their deviation degree (Fig. 4a). However, at the Xinquman station, the low pulse duration has a much higher deviation $(\mathrm{P}=\sim 170 \%)$ during the $\mathrm{RI}$ impacted period than $\mathrm{P}(\sim 90 \%)$ during the $\mathrm{CI}$ impacted period. (Fig. 4b). During the period of RI, the Alar station experienced a slightly increase in the low pulse counts, with the duration of low pulses remains unchanged (Table 3). The high pulses exhibited a positive increase in the counts and duration. During the $\mathrm{CI}$ impacted period, both the hydrologic stations show an increase in the number of low pulse counts and high pulse counts (Table 3). As the number of low pulse counts increasing, a dry and wet cycle will worsen the ecological natural development at the Tarim River floodplain. The moderate increase in the duration of high pulses may favor the riverine ecosystem. Because the increase of high pulse duration brings enough nutrients to the plants (especially the poplar) and animals along the river bank, and it may play a positive role in promoting the development of river biodiversity.

It seems that RI has more significant impact on the 4 indicators of Group 4 than CI does at both the Alar station and Xinquman station (Fig. 4c). CI and RI have much more significant impacts on the high pulse duration at the Xinquman station than at the Alar station (Fig. 4d).

Hydrologic alteration of rate and frequency of flow conditions change. Assessment of the Group 5 IHAs is listed in Table 3. Deviation degrees of rise rate and fall rate are negative at the two stations for the period of both RI and CI impacted periods, suggesting that both indicators were statistically reduced. On the other hand, deviation degrees of number of reversals are positive at the two stations for the period of both RI and CI impacted periods (Table 3). Note that deviation degrees of the Group 5 IHAs are very similar during the RI and CI impacted periods (Fig. 4a,b). At the Alar station, the number of reversals shows highly alteration $(\mathrm{D}=75 \%)$ during the $\mathrm{RI}$ impacted period and low alteration $(\mathrm{D}=24 \%)$ during the $\mathrm{CI}$ impacted period (Table 3$)$. At the Xinquman 
a) Alar

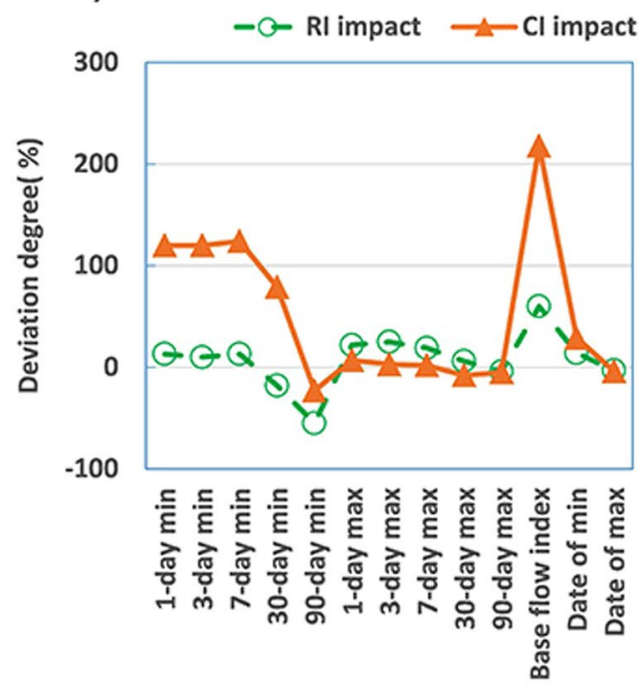

c)

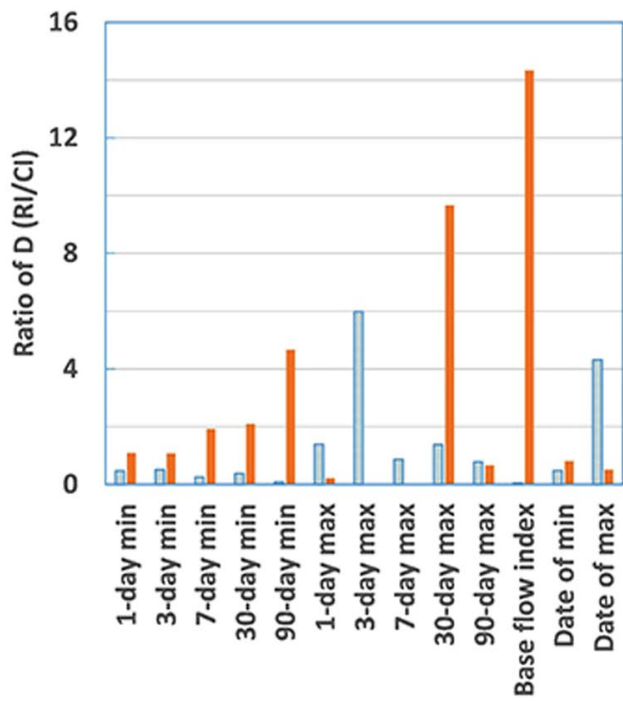

\section{b) Xinquman}

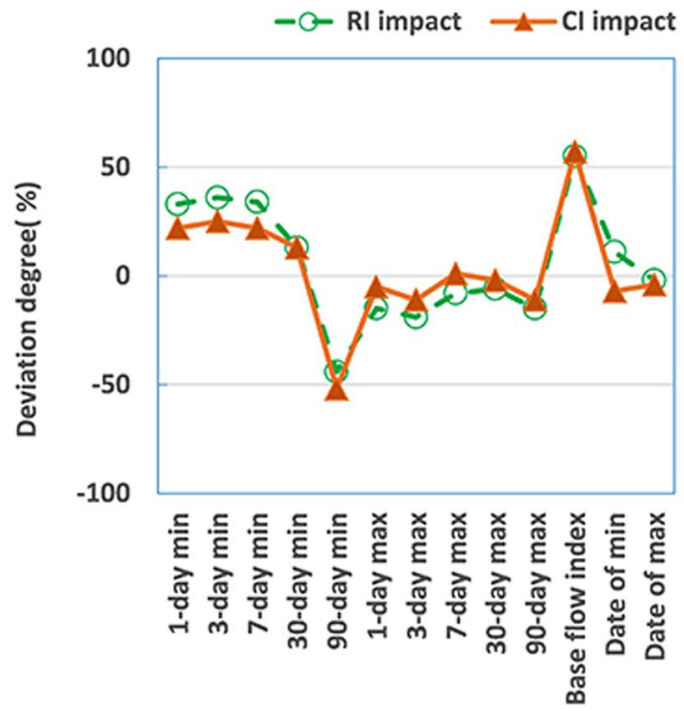

d)

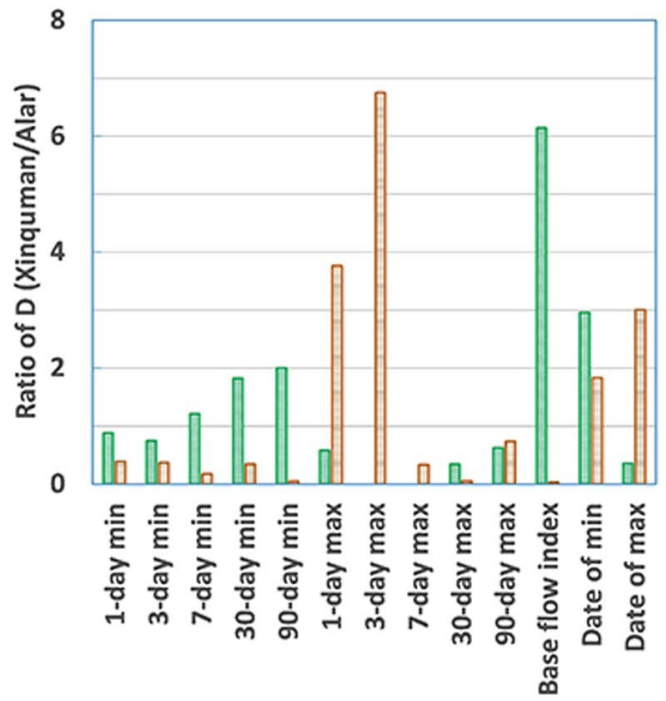

Figure 3. Plots of deviation degree of IHAs in Groups 2 and 3 at (a) the Alar station and (b) the Xinquman station, and ratio of degree of hydraulic alteration for (c) the RI impact to the CI impact and (d) the Alar station to the Xinquman station (note: RI for reservoir irrigation from 1973 to 1989 and CI for channel irrigation from 1995 to 2014).

station, both rise rate and fall rate show highly alteration during the $\mathrm{CI}$ impacted period. It seems that $\mathrm{RI}$ has more significant impacts on number of reversals at both stations than CI does (Fig. 4c). Both RI and CI show stronger alterations on the fall rate at the Xinquman station than at the Alar station.

Because of channel irrigation, fall rate of flow rate at the Xinquman station showed a significant increase trend from 2009 through 2012, even beyond the $25^{\text {th }}$ percentile (Fig. 5), suggesting that more actions should be taken to prevent deterioration in the ecohydrological system of the Tarim river because frequent fluctuation in the streamflow may destroy the stability of animal and plant habitats.

Overall degree of hydrologic alteration. Overall degree of hydrological alteration is shown in Fig. 6 with a proportion chart of IHAs at two hydrological stations at the two impacted periods: RI and CI. It can be seen that $34 \%$ to $48 \%$ of 32 indicators show low alteration, $31 \%$ to $37 \%$ with moderate alteration and $16 \%$ to $35 \%$ with highly alteration. This finding suggests the spatial-temporal hydrologic alterations in the Tarim River: 1) the Xinquman is further to the irrigation projects and has a smaller percentage of hydrological indicators with highly alteration and 2) CI has more impacts than RI, especially at the Xinquman station (Fig. 6).

Table 4 summarizes overall degree of hydrological alteration estimated for each group. The DHA of Group 1 indicators (the monthly flow rate) shows highly alteration with $\mathrm{D}>65 \%$ during the RI impacted period. The DHA of the Group 2 varies from 35\% to $41.8 \%$ at the Alar and Xinquman stations. During the RI impacted period 


\begin{tabular}{|c|c|c|c|c|c|c|c|c|c|c|c|c|c|c|}
\hline \multirow[b]{3}{*}{ Indicators } & \multicolumn{7}{|c|}{ The Alar station } & \multicolumn{7}{|c|}{ The Xinquman station } \\
\hline & \multirow{2}{*}{\begin{tabular}{|l|} 
Pre-impact \\
M \\
\end{tabular}} & \multicolumn{3}{|c|}{ RI impact } & \multicolumn{3}{|c|}{ CI impact } & \multirow{2}{*}{\begin{tabular}{|l|} 
Pre-impact \\
$M$
\end{tabular}} & \multicolumn{3}{|c|}{ RI impact } & \multicolumn{3}{|c|}{ CI impact } \\
\hline & & M & $\mathbf{P}(\%)$ & D (\%) & M & $\mathbf{P}(\%)$ & D (\%) & & M & $\mathbf{P}(\%)$ & D (\%) & M & $\mathbf{P}(\%)$ & D (\%) \\
\hline Low pulse count & 4.0 & 4.5 & 13 & 70 & 5.0 & 25 & 38 & 3.0 & 4.5 & 50 & 47 & 4.0 & 33 & 23 \\
\hline Low pulse duration & 13.0 & 13.0 & 0 & 54 & 10.5 & -19 & 10 & 9.0 & 24.5 & 172 & 34 & 17.0 & 89 & 18 \\
\hline High pulse count & 4.0 & 5.0 & 25 & 24 & 6.0 & 50 & 41 & 3.0 & 2.5 & -17 & 31 & 4.0 & 33 & 29 \\
\hline High pulse duration & 5.0 & 6.5 & 30 & 41 & 6.0 & 20 & 10 & 11.0 & 17.3 & 57 & 89 & 9.5 & -14 & 51 \\
\hline Rise rate & 5.0 & 2.7 & -46 & 24 & 2.1 & -58 & 74 & 3.4 & 1.5 & -55 & 43 & 1.1 & -67 & 88 \\
\hline Fall rate & -3.0 & -2.1 & -30 & 24 & -2.4 & -21 & 35 & -2.1 & -1.1 & -49 & 86 & -1.1 & -50 & 88 \\
\hline Number of reversals & \begin{tabular}{|l|}
69.0 \\
\end{tabular} & 89.0 & 29 & 75 & 78.5 & 14 & 24 & \begin{tabular}{|l|}
64.0 \\
\end{tabular} & 68.0 & 6 & 14 & 66 & 3 & 9 \\
\hline
\end{tabular}

Table 3. Comparison of hydraulic alterations for indicators in Groups 4 and 5 at the two stations for the preimpact, RI impact and CI impact.

(1973-1989), the ODHA reached 52.8\% and $46.4 \%$ at the Alar and Xinquman stations, both showing moderate alterations in the ecohydrologic conditions. The improved ODHA (IODHA) are $60.3 \%$ at the Alar station and $55.4 \%$ at the Xinquman station, higher alterations calculated with Equation (4), suggesting that ODHA may underestimate the degree of hydrologic alteration. During the CI impacted period (1995-2014), the IODHA are $68.7 \%$ at the Alar and $61.8 \%$ station at the Xinquman station.

The impact of climate change on the flow regime of the Tarim River. A hydrological flow regime may be altered by both human activities and climate change. In order to investigate impacts of climate change on the hydrological alterations, the precipitation data over the period of 1960 through 2014 from ten hydrological stations were analyzed. The annual precipitation at the upper reach of the Tarim River shows an overall increasing trend during the last 55 years, suggesting that climate change has a positive impact on the streamflow of the Tarim River (Fig. 7). Such an increase in the annual streamflow series at the up reach of the Tarim River is likely due to the fact that the increasing temperature at the study area which results in melting of more snow and ice at the mountainous area.

\section{Discussion}

This study presents assessment of hydrological alterations in the flow regime of the Tarim River over the past five decades in terms of 32 IHAs which have been commonly used to characterize an ecohydrological system. Our study confirms that the average monthly flow in Tarim River was greatly altered by human activities because of reservoir irrigation and channel irrigation. The average monthly flow rate decreased in most months, especially in March, June and August. At both the Alar and Xinquman stations, there was little change in the maximum monthly flow rate and the obvious increase in the minimum runoff was caused by reservoir irrigation. The date with a minimum runoff was delayed from late April to early May at the Alar station. The number of low pulse counts were increased. The number of reversal times were increased at the Xinquman station.

The impact of the reservoirs on the flow regime is more significant at the Alar than at the Xinquman due to the different spatial distribution. The overall degree of hydrologic alteration at Alar and Xinquman are $60.3 \%$ and 55.4\% respectively. During the CI impacted period from 1995 through 2014, the overall degree of hydrologic alteration at Alar and Xinquman are $68.7 \%$ and $61.8 \%$ respectively, which are both belong to highly alteration. Xinquman station, considering influence of interval water division irrigation projects, always exhibits a moderate alteration than the Alar station.

The relationship between hydrological processes and ecological system is tightly influenced by human-induced stresses such as reservoir construction, farmland irrigation, urban water supply and flood control. The well-known streamflow characteristics including hydrologic event magnitude, frequency, timing, duration and rates of change are often closely connected to river habitat variation. According to the response mechanism of ecological system reflected by the above mentioned characteristics, the effects of water conservancy projects on the ecological system in the TRB are mainly summarized as follows: (1) The reduction of streamflow in most months is likely contributing to the frequent change of drought and wet in different seasons. The decrease of summer flow in several days may leads to negative effects on the aquatic habitat, migratory and reproductive for fish species in downstream channel. (2) The reduction in 1-day maximum flow at the Xinquman station is likely restricting the nutrients transportation corridor between riverbed and floodplains. (3) Julian date of minimum streamflow lagged 41 days behind the nature state at the Alar station, which may threaten the riverine living environments, including the surrounding vegetation and aquatic organisms.

With the aim to storage water in flood season and reduce flood disaster reasonably, some typical reservoirs and lots of diversion plots are constructed and operated sequentially, which is a driving force of hydrologic regime in riverine ecosystems. Our study clearly shows that inappropriate management of water conservancy projects could dramatically alter the hydrological regime of the Tarim River. Our results presented in this study may provide a guidance in designing strategies to recover the ecohydrological system of the Tarim River, as well as those rivers at arid areas in the world.

\section{Materials and Methods}

Study area. The Tarim River, located in the southern Xinjiang Province, is the longest inland river in China. Its mainstream begins from the west of the junction of Yarkant River, Hotan River and Akesu River and empties to 
a) Alar

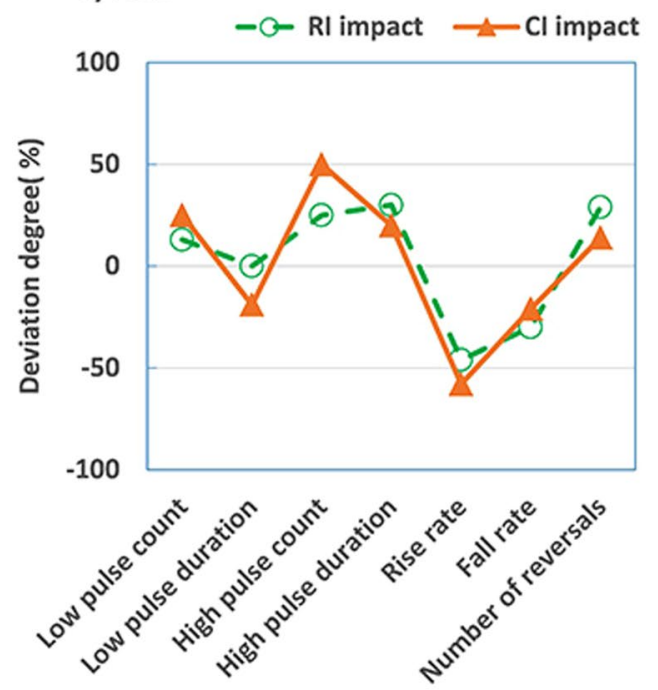

c)
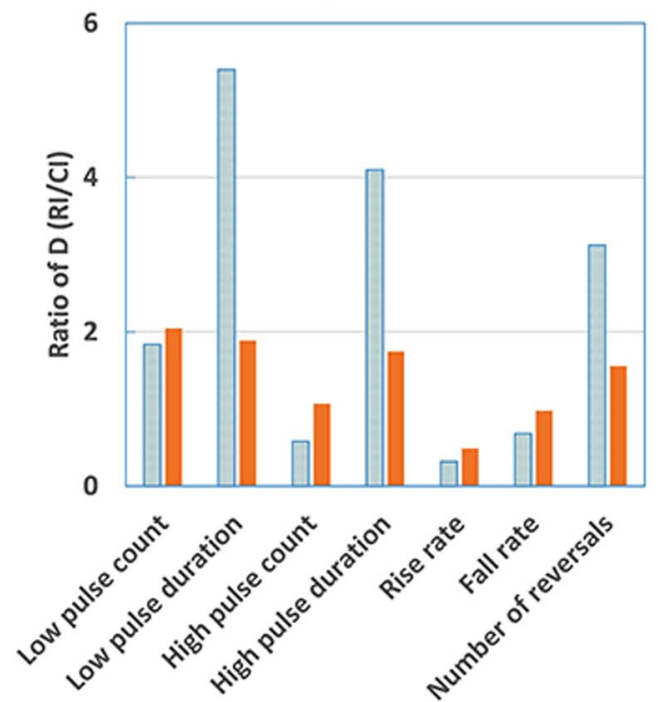

b) Xinquman

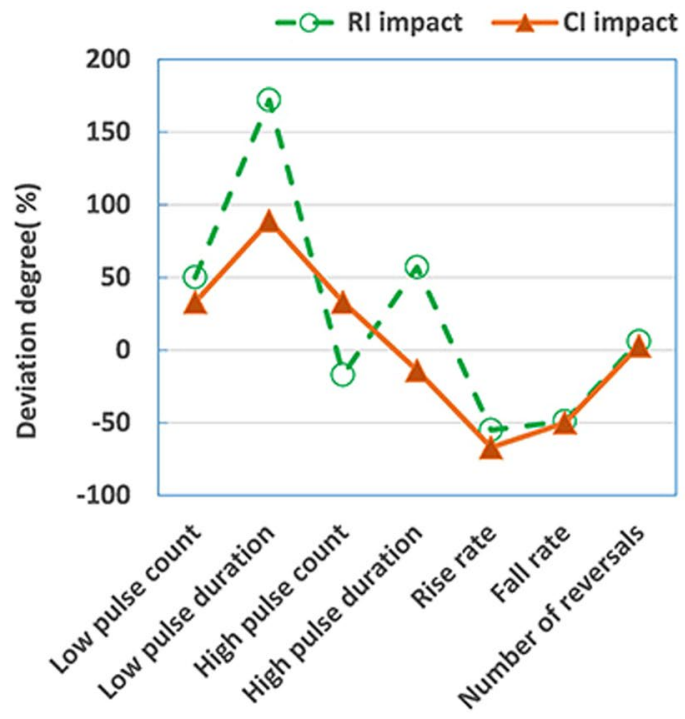

d)

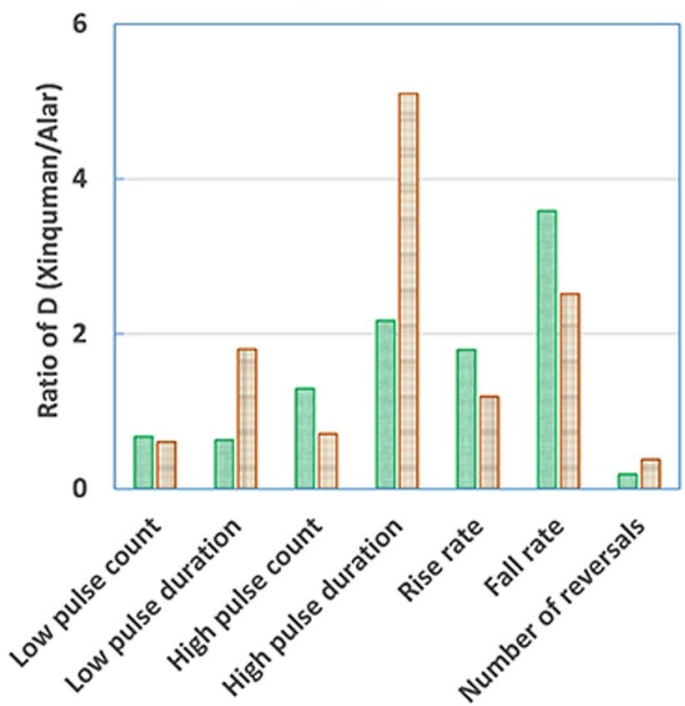

Figure 4. Plots of deviation degree of IHAs in Groups 4 and 5 at (a) the Alar station and (b) the Xinquman station, and ratio of degree of hydraulic alteration for (c) the RI impact to the CI impact and (d) the Alar station to the Xinquman station (note: RI for reservoir irrigation from 1973 to 1989 and CI for channel irrigation from 1995 to 2014$)$.

the Taitema Lake ${ }^{37}$, with a total length of $1321 \mathrm{~km}$, as shown in Fig. 8. The Tarim River is supplied by ice and snow melting and precipitation in the mountains with a drainage area of approximately 1.02 million $\mathrm{km}^{2}$. The Tarim Basin has an extreme drought desert climate. The average annual temperature is about $10.6^{\circ} \mathrm{C}$ to $11.5^{\circ} \mathrm{C}$ with monthly mean temperature ranging from $20^{\circ} \mathrm{C}$ to $30^{\circ} \mathrm{C}$ in July and $-10^{\circ} \mathrm{C}$ to $-20^{\circ} \mathrm{C}$ in January ${ }^{26}$. Compared to the average annual precipitation of $200-300 \mathrm{~mm}$ in the mountainous headwater regions ${ }^{37}$, the average annual precipitation at the mainstream area of the Tarim River is only about $50-80 \mathrm{~mm}$. The annual potential evaporation ranges from $2000 \mathrm{~mm}$ to $2900 \mathrm{~mm}$.

Agriculture is the main economic activity at the Tarim River Basin and heavily relies on various water diversion projects for irrigation in the Tarim River. The water diversion projects for irrigation include two main types: reservoir irrigation and channel irrigation. The reservoir irrigation is mainly to transport water through diversion canals and store in plain reservoirs for further irrigation usage while channel irrigation is to drain water directly from the river for irrigation without storage in a reservoir. There are two main reservoirs which were built for irrigation purpose. The Duolang Reservoir ${ }^{45}$ is located at $40 \mathrm{~km}$, northwest to the Alar city and consists of an old reservoir built in 1965 and a new reservoir built in 1995. It is worth mentioning that the storage capacity turned to 43 million $\mathrm{m}^{3}$ after the expansion in 1971 and total reservoir capacity is approximately 120 million $\mathrm{m}^{3}$ since 1995 . The Shengli Reservoir ${ }^{46}$, located about $30 \mathrm{~km}$, west to the Alar city, was built in 1965 with a capacity of approximately 108 million $\mathrm{m}^{3}$, and it began to storage water by the end of 1970 . In the upper reach of the 


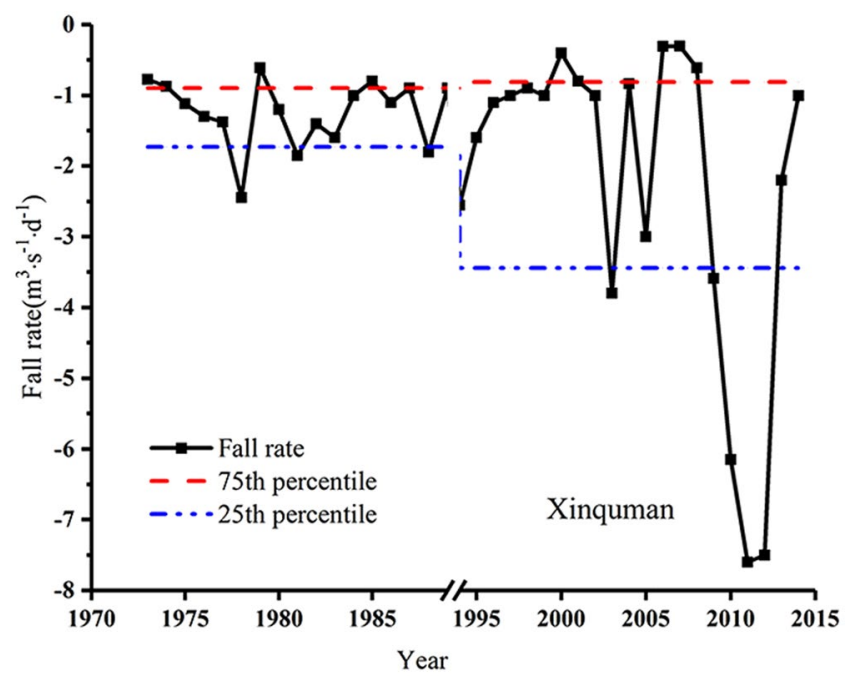

Figure 5. The average flow reduction rate during 1973 to 2014 at Xinquman station.

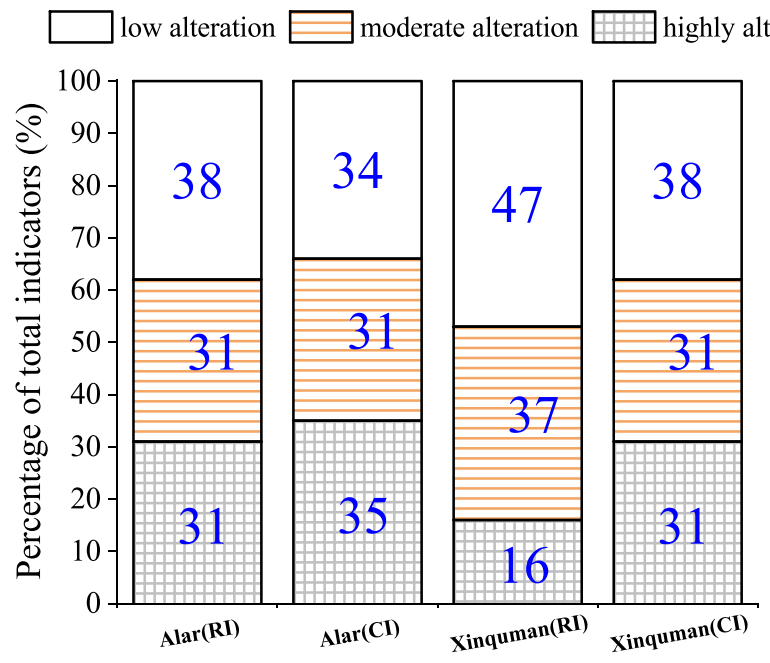

Hydrological station

Figure 6. Bar plot of percentage of IHAs that are categorized into three ranks during the RI impacted period and the CI impacted period at the Alar and Xinquman stations.

\begin{tabular}{|l|l|l|l|l|l|l|l|l|}
\hline & \multirow{2}{*}{} & \multirow{2}{*}{ hydrologic station } & \multicolumn{2}{|l|}{ Degree of Hydrologic Alteration (\%) } & \multirow{2}{*}{} & \multirow{2}{*}{ IODHA } \\
\cline { 3 - 8 } & Group 1 & Group 2 & Group 3 & Group 4 & Group 5 & ODHA & IOD \\
\hline RI Impact & 65.3 & 41.8 & 32.1 & 50.2 & 47.1 & $52.8(\mathrm{M})$ & $60.3(\mathrm{H})$ \\
\hline$(1973-1989)$ & Xinquman & 48.8 & 35.0 & 51.5 & 55.2 & 55.9 & $46.4(\mathrm{M})$ & $55.4(\mathrm{M})$ \\
\hline CI Impact & Alar & 75.1 & 73.5 & 34.5 & 28.8 & 49.3 & $66.2(\mathrm{H})$ & $68.7(\mathrm{H})$ \\
\hline$(1995-2014)$ & Xinquman & 74.7 & 33.7 & 65.0 & 32.8 & 71.9 & $58.0(\mathrm{M})$ & $61.8(\mathrm{H})$ \\
\hline
\end{tabular}

Table 4. Overall degree of hydrological alteration in the Tarim River for the RI impact and the CI impact. Note: ODHA represents the overall degree of hydrological alteration estimated with Equation (3) and IODHA is for the improved overall degree of hydrological alteration estimated with Equation (4). For each group, the degree of hydrologic alteration (DHA) was estimated using Equation (3).

Xinquman station, several water diversion irrigation projects were built during 1989-1994. Note that the water diversion projects were not operated in a well-controlled manner according to the data from the Tarim River Basin management Bureau ${ }^{47}$. 


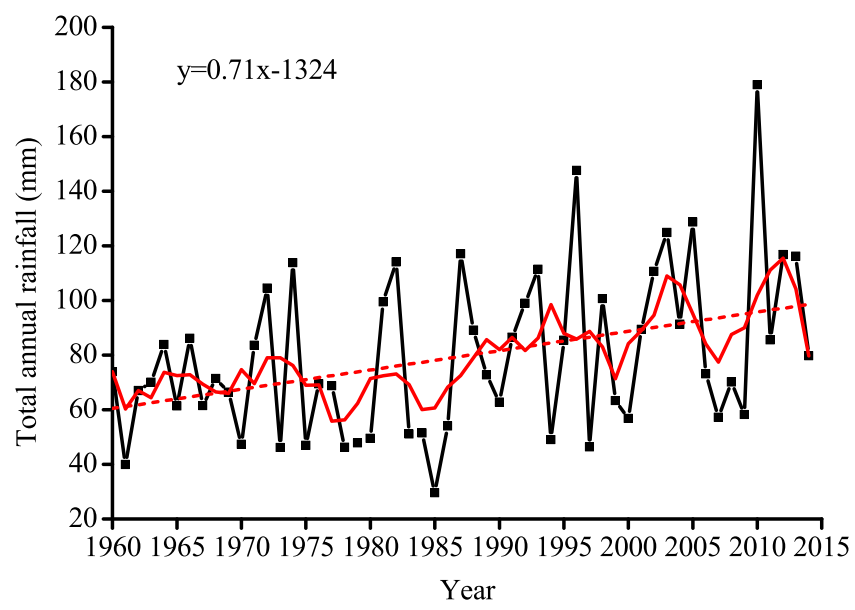

Figure 7. Temporal trend in annual precipitation at the upper reach of the Tarim River over 55 years (dash line is the linear fitting for the annual precipitation over 55 years with a slope of 0.71 ).

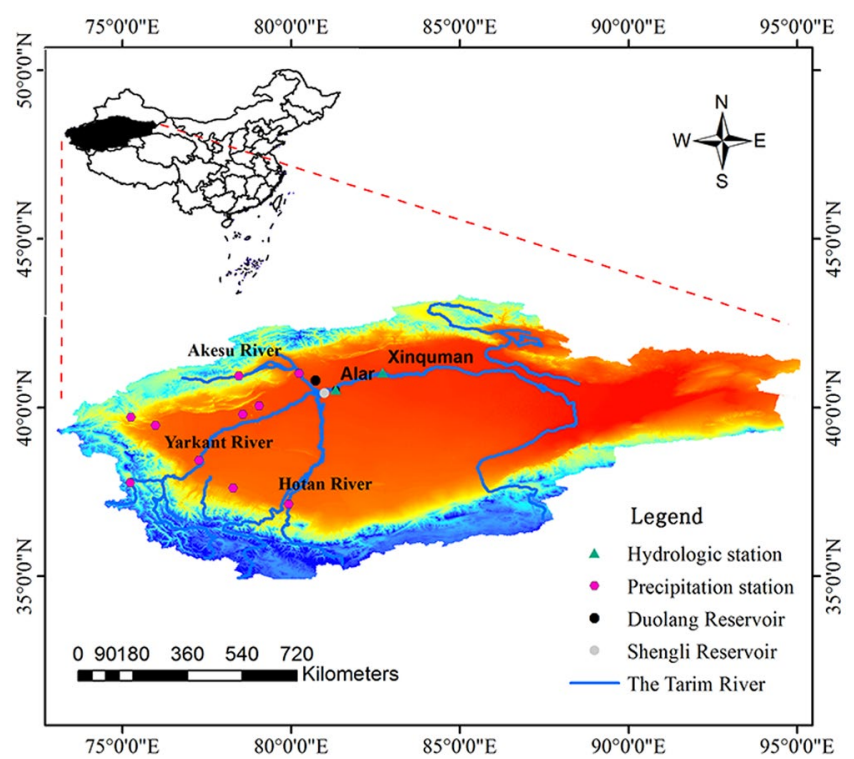

Figure 8. Sketch map of the Tarim River Basin and locations of hydrologic stations. (The map was generated with data available from the Chinese Geospatial Data Cloud using ESRI's ArcGIS (version 10.1; http://www.gscloud.cn/)).

Data. The ArcGIS 10.1 and downloaded DEM data (http://www.gscloud.cn/) of the Tarim Basin with a resolution of $90 \mathrm{~m}$ were used to extract drainage network (Fig. 8). Daily streamflow data collected from the two representative hydrological stations, the Alar station and the Xinquman station on the mainstream of the Tarim Basin during 1957-2014 were analyzed, in addition to the construction years of water diversion irrigation projects from 1990 through 1994. Based on operation time of the plain reservoirs and the water diversion irrigation projects, the streamflow data were divided into three periods: the pre-impact period (from 1957 through 1972), representing impact of natural flow regimes; the reservoir irrigation (RI) impact period (from 1973 through 1989) for water diversion from the mainstream of the Tarim River mainly transferred to plain reservoirs, and the channel irrigation (CI) period (from 1995 through 2014).

\section{Methods}

The set of indicators of hydrological alteration, initially proposed by Richter et al. ${ }^{16}$ are used in this study to assess impacts of human activities (reservoir irrigation and channel irrigation) on flow regimes of the Tarim River. The IHAs are categorized into 5 groups for characterizing a flow regime in terms of magnitude of monthly flow, magnitude and duration of annual extreme flows and the base flow condition, timing of annual extreme flow conditions, frequency and duration of high and low pulses, and rate and frequency of flow changes (Table 5). Based on initial screening of daily streamflow data from the Alar station and the Xinquman station, the indicator of zero flow days is excluded and therefore only 32 indicators are assessed for characterization of the flow regime in the Tarim River. 


\begin{tabular}{|l|l|l|}
\hline Group & Group description & Hydrological indicators \\
\hline Group 1 (12 IHAs) & Magnitude of monthly flow & Average flow of each calendar month \\
\hline Group 2 (11 IHAs) & $\begin{array}{l}\text { Magnitude and duration of annual extreme } \\
\text { flows, and the base flow condition }\end{array}$ & $\begin{array}{l}\text { Annual minimum 1-, 3-, 7-, 30-, 90-day means Annual } \\
\text { maximum 1-, 3-, 7-, 30-, 90-day means Base flow index }\end{array}$ \\
\hline Group 3 (2 IHAs) & Timing of annual extreme flow conditions & $\begin{array}{l}\text { Julian date of annual 1-day minimum Julian date of } \\
\text { annual 1-day maximum }\end{array}$ \\
\hline Group 4 (4 IHAs) & Frequency and duration of high and low pulses & $\begin{array}{l}\text { Number of low pulses each year. Mean duration of low } \\
\text { pulse with each year. Number of high pulses each year. } \\
\text { Mean duration of high pulse with each year }\end{array}$ \\
\hline Group 5 (3 IHAs) & Rate and frequency of flow changes & Rise rate. Fall rate. Number of flow reversals \\
\hline
\end{tabular}

Table 5. Indicators of hydrological alteration (32 IHAs).

\begin{tabular}{|l|l|l|l|l|l|}
\hline Grade & slight alteration & low alteration & moderate alteration & highly alteration & severe alteration \\
\hline$D$ & $<20 \%$ & $20-40 \%$ & $40-60 \%$ & $60-80 \%$ & $>80 \%$ \\
\hline
\end{tabular}

Table 6. Classification of the improved overall degree of hydrological alteration.

To quantitatively compare impacts of human activities on IHAs, each IHA is calculated in terms of median value, deviation degree, and degree of hydrological alteration at the three periods: the pre-impacted, the reservoir irrigation (RI) impacted and channel irrigation (CI) impacted. The deviation degree for an IHA is calculated with the following equation,

$$
P_{i}=\frac{M_{e}-M_{o}}{M_{o}} \times 100 \%
$$

where $M_{o}$ and $M_{e}$ are the median value for the pre-impacted and the post-impacted period which refers to either RI impacted or CI impacted. A positive $P_{i}$ indicates an increased median value in the post-impacted period compared to the pre-impacted period while a negative $P_{i}$ suggests a decreased median value in the post-impacted period compared to the pre-impacted period. Degree of hydrological alteration of a flow regime can be further calculated for each indicator according to the following equation ${ }^{15}$,

$$
D_{i}=\left|\frac{N_{o}-N_{e}}{N_{e}}\right| \times 100 \%
$$

where $N_{o}$ is the observed number of post-impacted years for which the value of the indicator falls within the RVA target range, from $25^{\text {th }}$ percentile to $75^{\text {th }}$ percentile, as suggested by Richter et al. ${ }^{15} . N_{e}$ is the expected number of post impacted years for which the value of indicator falls within the targeted range and can be estimated by $r \times N_{T}$ ( $\mathrm{r}$ is percentage of pre-impacted years for which the value of an indicator falls within the RVA target range, and $\mathrm{N}_{\mathrm{T}}$ is total number of post impacted years). Generally, RVA presumes natural flow series of a flow regime to be an ideal condition. If an environmental flow scheme attains a preset target range at a same frequency as that occurred naturally, then the flow regime is expected to be healthy. It is suggested that $D_{i}<33 \%$ for little or no alteration, $33 \%<D_{i}<67 \%$ for moderate alteration, and $D_{i}>67 \%$ for high alteration ${ }^{15}$. However, Equation (2) is used to estimate $D_{i}$ for each of 32 indicators. Some ${ }_{i}$ ndicators may show low alteration in a flow regime while some other may have a highly degree of alteration. An overall degree of hydrological alteration for all 32 indicators can be calculated according to the following equation,

$$
D=\sqrt{\frac{\sum_{i=1}^{32} D_{i}^{2}}{32}}
$$

One limitation to use Equation (3) for calculating the overall degree of hydrological alteration is that the impact of an indicator having highly degree of alteration on the flow regime could be easy underestimated among most indicators having a moderate (or low) degree of alteration. In order to overcome the limitation in Equation (3), an improved overall degree of hydrologic alteration is calculated according to the following equation,

$$
D=\sqrt{\frac{D_{\text {jmax }}^{2}+D_{w}^{2}}{2}}
$$

where $D_{\text {jmax }}$ and $D_{w}$ are the maximum and average values of degree of alteration for the each group of indicators. In this study, the impacts of water diversion projects on the flow regime in the Tarim River is evaluated based on the improved overall degree of alteration, estimated using Equation (4) and classified into 5 groups: slightly alteration, low alteration, moderation alteration, highly alteration and severe alteration(Table 6). 


\section{References}

1. Liu, J. \& Yang, W. Water Sustainability for China and Beyond. Science. 337, 649-650 (2012).

2. Zhao, X. et al. Physical and virtual water transfers for regional water stress alleviation in China. Proceedings of the National Academy of Sciences. 112, 1031-1035 (2015).

3. Cheng, H., Hu, Y. \& Zhao, J. Meeting China’s Water Shortage Crisis: Current Practices and Challenges. Environ Sci Tech. 43, 240-244 (2009).

4. Varis, O. \& Vakkilainen, P. China's 8 challenges to water resources management in the first quarter of the 21 st Century. Geomorphology. 41, 93-104 (2001).

5. Bunn, S. E. \& Arthington, A. H. Basic Principles and Ecological Consequences of Altered Flow Regimes for Aquatic Biodiversity. Environmental Management. 30, 492-507 (2002).

6. Lytle, D. A. \& Poff, N. L. Adaptation to natural flow regimes. Trends in Ecology \& Evolution. 19, 94-100 (2004).

7. Poff, N. L. \& Zimmerman, J. K. H. Ecological responses to altered flow regimes: a literature review to inform the science and management of environmental flows. Freshwater Biology. 55, 194-205 (2010).

8. Gao, Y., Vogel, R. M., Kroll, C. N., Poff, N. L. \& Olden, J. D. Development of representative indicators of hydrologic alteration. Journal of Hydrology. 374, 136-147 (2009).

9. Olden, J. D. \& Poff, N. L. Redundancy and the choice of hydrologic indices for characterizing streamflow regimes. River Research and Applications. 19, 101-121 (2003).

10. Yang, Z., Yan, Y. \& Liu, Q. Assessment of the flow regime alterations in the Lower Yellow River, China. Ecological Informatics. 10, 56-64 (2012)

11. Chen, Y. D. et al. Hydrologic alteration along the Middle and Upper East River (Dongjiang) basin, South China: a visually enhanced mining on the results of RVA method. Stochastic Environmental Research and Risk Assessment. 24, 9-18 (2010).

12. Kim, B.-S., Kim, B.-K. \& Kwon, H.-H. Assessment of the impact of climate change on the flow regime of the Han River basin using indicators of hydrologic alteration. Hydrological Processes. 25, 691-704 (2011).

13. Mathews, R. \& Richter, B. D. Application of the Indicators of Hydrologic Alteration Software in Environmental Flow Setting1. Journal of the American Water Resources Association. 43, 1400-1413 (2007).

14. Richter, B. D., Baumgartner, J. V., Wigington, R. \& Braun, D. P. How much water does a river need? Freshwater Biology. 37, 231-249 (1997).

15. Richter, B. D., Baumgartner, J. V., Braun, D. P. \& Powell, J. A spatial assessment of hydrologic alteration within a river network. Regulated Rivers: Research \& Management. 14, 329-340 (1998).

16. Richter, B. D., Baumgartner, J. V., Powell, J. \& Braun, D. P. A Method for Assessing Hydrologic Alteration within Ecosystems. Conservation Biology. 10, 1163-1174 (1996).

17. Yang, T. et al. A spatial assessment of hydrologic alteration caused by dam construction in the middle and lower Yellow River, China. Hydrological Processes. 22, 3829-3843 (2008).

18. Shiau, J.-T. \& Wu, F.-C. Feasible Diversion and Instream Flow Release Using Range of Variability Approach. Journal of Water Resources Planning and Management 130, 395-404 (2004).

19. Shiau, J.-T. \& Wu, F.-C. A Histogram Matching Approach for assessment of flow regime alteration: application to environmental flow optimization. River Research and Applications. 24, 914-928 (2008).

20. Yang, P., Yin, X.-A., Yang, Z.-F. \& Tang, J. A revised range of variability approach considering the periodicity of hydrological indicators. Hydrological Processes. 28, 6222-6235 (2014).

21. Chen, Y. et al. Response of riparian vegetation to water-table changes in the lower reaches of Tarim River, Xinjiang Uygur, China. Hydrogeo J. 16, 1371-1379 (2008)

22. Wang, H., Chen, Y., Deng, H. \& Pan, Y. Detecting changes in extreme streamflow in the Tarim River, Northwest China. Quaternary International. 380-381, 149-158 (2015).

23. Ye, Z., Chen, Y. \& Li, W. Ecological water rights and water-resource exploitation in the three headwaters of the Tarim River. Quaternary International. 336, 20-25 (2014).

24. Aishan, T. et al. Monitoring the hydrological and ecological response to water diversion in the lower reaches of the Tarim River, Northwest China. Quaternary International. 311, 155-162 (2013).

25. Bai, Y., Xu, H. \& Ling, H. Drought-flood variation and its correlation with runoff in three headstreams of Tarim River, Xinjiang, China. Environ Earth Sci. 71, 1297-1309 (2014).

26. Chen, Y.-n., Li, W.-h., Xu, C.-c. \& Hao, X.-m. Effects of climate change on water resources in Tarim River Basin, Northwest China. Journal of Environmental Sciences 19, 488-493 (2007).

27. Chen, Y., Xu, C., Chen, Y., Liu, Y. \& Li, W. Progress, Challenges and Prospects of Eco-Hydrological Studies in the Tarim River Basin of Xinjiang, China. Environmental Management. 51, 138-153 (2013).

28. Grashey-Jansen, S., Kuba, M., Cyffka, B., Halik, Ü. \& Aishan, T. Spatio-temporal variability of soil water at three seasonal floodplain sites: A case study in Tarim Basin, Northwest China. Chinese Geographical Science. 24, 647-657 (2014).

29. Guo, H. et al. Effects of the Tarim River's middle stream water transport dike on the fractional cover of desert riparian vegetation. Ecol. Eng. 99, 333-342 (2017).

30. Hartmann, H. et al. Predictors of precipitation for improved water resources management in the Tarim River basin: Creating a seasonal forecast model. Journal of Arid Environments. 125, 31-42 (2016a).

31. Hartmann, H., Snow, J. A., Su, B. \& Jiang, T. Seasonal predictions of precipitation in the Aksu-Tarim River basin for improved water resources management. Global and Planetary Change. 147, 86-96 (2016b).

32. Liu, Y. \& Chen, Y. Impact of population growth and land-use change on water resources and ecosystems of the arid Tarim River Basin in Western China. International Journal of Sustainable Development \& World Ecology. 13, 295-305 (2006).

33. Lyu, J., Shen, B. \& Li, H. Dynamics of major hydro-climatic variables in the headwater catchment of the Tarim River Basin, Xinjiang, China. Quaternary International. 380-381, 143-148 (2015).

34. Tao, H., Gemmer, M., Bai, Y., Su, B. \& Mao, W. Trends of streamflow in the Tarim River Basin during the past 50 years: Human impact or climate change? Journal of Hydrology. 400, 1-9 (2011).

35. Wu, J. Evaluation of the water resource reproducible ability on Tarim River Basin in south of Xinjiang, northwest China. Environ Earth Sci. 66, 1731-1737 (2012).

36. Xu, Z. X., Chen, Y. N. \& Li, J. Y. Impact of Climate Change on Water Resources in the Tarim River Basin. Water Resour Manag. 18, 439-458 (2004).

37. Yu, G.-A., Disse, M., Huang, H. Q., Yu, Y. \& Li, Z. River network evolution and fluvial process responses to human activity in a hyper-arid environment - Case of the Tarim River in Northwest China. CATENA. 147, 96-109 (2016).

38. Zhang, Q., Xu, C.-Y., Tao, H., Jiang, T. \& Chen, Y. D. Climate changes and their impacts on water resources in the arid regions: a case study of the Tarim River basin, China. Stochastic Environmental Research and Risk Assessment. 24, 349-358 (2010).

39. Zhang, X., Chen, Y., Li, W., Yu, Y. \& Sun, Z. Restoration of the lower reaches of the Tarim River in China. Regional Environmental Change. 13, 1021-1029 (2013).

40. Zhou, H., Zhang, X., Xu, H., Ling, H. \& Yu, P. Influences of climate change and human activities on Tarim River runoffs in China over the past half century. Environ Earth Sci. 67, 231-241 (2012).

41. Chen, Y., Ye, Z. \& Shen, Y. Desiccation of the Tarim River, Xinjiang, China, and mitigation strategy. Quaternary International. 244, 264-271 (2011). 
42. Qi, F. et al. Environmental effects of water resource development and use in the Tarim River basin of northwestern China. Environ. Geol. 48, 202-210 (2005).

43. Tao, H., Gemmer, M., Song, Y. \& Jiang, T. Ecohydrological responses on water diversion in the lower reaches of the Tarim River, China. Water Resour. Res. 44, W08422 (2008).

44. Sun, P., Zhang, Q., Lu, X. \& Bai, Y. Changing properties of low flow of the Tarim River basin: Possible causes and implications. Quaternary International. 282, 78-86 (2012).

45. Li, Z. R., Ji, J. \& Chai, J. J. Discussion on the application effect of the external flood diversion project of Duolang reservoir. China Rural Water and Hydropower. 19, 126-127 (2001).

46. Deng, M. Water resources management of the Tarim River Basin in future. Water Resour Manag. 17, 20-23 (2004).

47. Wang, Y. \& Hu, C. Study on irrigation diversion and its influence on the mainstream Tarim River. Water Resources and Hydropower Engineering. 34, 48-51 (2003).

\section{Acknowledgements}

This study was supported by the National Scientific Foundation of China (NSFC) (No.41371052, U1203282, No.51269026). Ministry of Water Resources' special funds for scientific research on public causes (201501059). The authors are very grateful to the supporting sponsored by Qing Lan Project of Jiangsu Province.

\section{Author Contributions}

Lianqing Xue and Hui Zhang conceived and designed the research themes; Changbing Yang and Hui Zhang analyzed the data; Hui Zhang, Luochen Zhang and Chao Sun contributed to data preparation; Lianqing Xue wrote the paper. All authors have contributed to the revision and approved the manuscript.

\section{Additional Information}

Competing Interests: The authors declare that they have no competing interests.

Publisher's note: Springer Nature remains neutral with regard to jurisdictional claims in published maps and institutional affiliations.

Open Access This article is licensed under a Creative Commons Attribution 4.0 International License, which permits use, sharing, adaptation, distribution and reproduction in any medium or format, as long as you give appropriate credit to the original author(s) and the source, provide a link to the Creative Commons license, and indicate if changes were made. The images or other third party material in this article are included in the article's Creative Commons license, unless indicated otherwise in a credit line to the material. If material is not included in the article's Creative Commons license and your intended use is not permitted by statutory regulation or exceeds the permitted use, you will need to obtain permission directly from the copyright holder. To view a copy of this license, visit http://creativecommons.org/licenses/by/4.0/.

(C) The Author(s) 2017 